\title{
Comparison of efficacy of buccal versus vaginal misoprostol in first trimester induced abortion
}

\author{
Nida Khan ${ }^{1 *}$, Anita M. Kant ${ }^{1}$, Pooja C. Thukral' ${ }^{1}$, Mohammad Saquib ${ }^{2}$
}

\begin{abstract}
${ }^{1}$ Department of Obstetrics and Gynecology, Asian Institute of Medical Sciences, Faridabad, Haryana, India
${ }^{2}$ Department of Surgery, Hamdard Institute of Medical Sciences and Research, New Delhi, India
\end{abstract}

Received: 23 May 2019

Accepted: 16 July 2019

\section{*Correspondence:}

Dr. Nida Khan,

E-mail: docnida227@gmail.com

Copyright: (C) the author(s), publisher and licensee Medip Academy. This is an open-access article distributed under the terms of the Creative Commons Attribution Non-Commercial License, which permits unrestricted non-commercial use, distribution, and reproduction in any medium, provided the original work is properly cited.

\begin{abstract}
Background: To compare the effectiveness, side effects, and patient satisfaction of buccal versus vaginal misoprostol administration in first trimester abortions.

Methods: Women opting for first trimester abortion received oral Mifepristone followed 48 hours latermisoprostol. Group A received Misoprostol via buccal route whereas group B received Misoprostol vaginally. A comparative analysis using SPSS was done.

Results: Giving $800 \mu \mathrm{g}$ Misoprostol by either buccal or vaginal route after oral Mifepristone have comparable efficacy in terms of complete abortion rate ( $96 \%$ in buccal group versus $98 \%$ in vaginal group; $p$ value $=0.495)$, failure rate being statistically similar (4\% versus $2 \%$ ). Drug abortion interval was comparable in the two groups. (11.16 hour in buccal group and 12.32 hours in vaginal group). Few side effects like nausea and vomiting, shivering, diarrohea was significantly higher with vaginal Misoprostol while abdominal cramps, altered taste were found more with the buccal group.

Conclusions: Buccal Misoprostol is comfortable and easier to administer when compared to other routes and it has potential to be developed as a self-administered regimen. Buccal Misoprostol is as efficacious as vaginal Misoprostol with significantly lesser side effects up to 7 weeks of period of gestation.
\end{abstract}

Keywords: Abortions, Buccal, Comparative analysis, First trimester, Misoprostol, Vaginal

\section{INTRODUCTION}

Safe abortion has been defined by WHO as "abortion provided through approved facilities and/or person". The price that women pay simply for being women is unfortunately a nightmare which is appallingly true. The demands of procreation and childbirth take a heavy toll on women's life. One of the most preventable tragedies for womankind is the problem of unwanted pregnancy and unsafe abortion. Approximately 41.6 million abortions occur annually and nearly 19 million of them are unsafe. ${ }^{1}$ Medical abortion is a safe alternative to surgical methods. MTP was legalized in India in the year
1971. ${ }^{2}$ In 2002 and 2003, an amendment to the MTP Act sanctioned obstetrician-gynecologists to provide Mifepristone and Misoprostand after 6 weeks or in a clinical setting up to 7 weeks of pregnancy. Medical abortion, also known as abortion by medication or medical method of abortion is a revolution in women's reproductive health. It refers to pregnancy termination with abortion inducing medications without surgical intervention. A variety of medical abortion regimens have been developed and their efficacy depends primarily on the dose, type, timing and route of administration of the prostaglandin used with mifepristone. Currently, most medical abortion protocols use Mifepristone orally with 
Misoprostol administered vaginally. Healthcare organizations providing medical abortions have been interested in alternatives to the vaginal administration of Misoprostol for several reasons. One alternative to the vaginal route has been the oral administration of Misoprostol, the regimen on which US Food and Drug Administration approval was based. A more recent regimen is buccal administration of Misoprostol. Amongst the many benefits of the buccal route over the vaginal route include its ease of administration and lesser infection rate. ${ }^{3}$ The present study is an attempt to determine the efficacy of buccal route of Misoprostol as an alternative to vaginal administration of Misoprostol for pregnancy termination in first trimester.

\section{METHODS}

The study was a single-center, prospective and interventional randomised comparative study. One hundred women were selected for first trimester induced abortions by medicine. Two groups were made and women were assorted to one of the groups by block randomization. Group A constituted 50 women with abortions induced by Misoprostol given by buccal route and Group B constituted 50 women with abortions induced by Misoprostol given by vaginal route. Mifepristone administration by oral route 48 hours earlier in either group.

\section{Inclusion criteria}

- $\quad$ Age 18 years and above

- Requesting for an elective termination of pregnancy well within the MTP Act

- An intrauterine singleton pregnancy of less than or equal to 49 days and also confirmed by ultrasonography

- Willing to undergo required follow up in OPD

- Should be willing to undergo surgical procedure, in case the medical method fails or results in incomplete abortion

- Should have access to telephone call and emergency medical treatment in case of excessive bleeding or pain etc.

\section{Exclusion criteria}

- Contraindication to misoprostol (glaucoma, mitral stenosis, sickle cell anemia, poorly controlled seizure disorders or known allergy to prostaglandins)

- Any attempt of prior intervention in the present pregnancy

- Known or suspected extrauterine pregnancy

- Known or suspected pelvic infection

- Hemoglobin $<10 \mathrm{~g} / \mathrm{dl}$

- Known clotting defect/receiving anticoagulation therapy/ inherited porphyria
- Cardiovascular disease (angina, valvular disease, arrhythmia or cardiac failure)

- Chronic renal insufficiency

- Undiagnosed adnexal mass

- Lack of access to emergency care

- Adrenal insufficiency

- Rhesus negative subjects received anti-D immune globulin.

After the approval of study by Institutional ethics committee, a written informed consent was taken from the patients who satisfied the inclusion criteria and each patient had the right to deny participation. Demographic details like age, parity, rural/urban, period of amenorrhea, menstrual history, and detailed present and past obstetric history (including previous abortions) was taken. General physical and systemic examination was carried out. Investigations like haemoglobin, blood group and ultrasound (to confirm intrauterine pregnancy and period of gestation) were done and $200 \mathrm{mg}$ Mifepristone was given on day 1 .

- Group A: Patients falling in this group received 200 mg Mifepristone orally and were asked to report 48 hours later for Misoprostol administration by buccal route. Four tablets of Misoprostol (200 mcg each) were placed in the buccal pouch i.e., between teeth and cheek. Women were instructed to swallow any remaining pill fragments after 30 minutes.

- Group B: Patients falling in this group also received $200 \mathrm{mg}$ Mifepristone orally and were asked to report 48 hours later for Misoprostol administration by vaginal route. Four tablets of $200 \mathrm{mcg}$ each (total $800 \mathrm{mcg}$ ) of Misoprostol were inserted vaginally. Subjects remained supine for 30 minutes before going home. Drug-related adverse effects and patient satisfaction were recorded in subjects in both the groups.

\section{Follow-up}

Subjects were asked to return for examination on $2^{\text {nd }}, 14^{\text {th }}$ day, and after 6 weeks or after menses or in between if they had any complaints. Ultra-sonography was carried out on day 14 to look for any retained products of conception. The main outcome was defined as successful if a complete abortion without surgical intervention was achieved.

\section{Patients were enquired about the following}

- Drug abortion interval

- Amount of bleeding (estimated by number of pads, clots)and duration of bleeding

- Need for analgesia

- Presence of side effects (nausea and vomiting requiring antiemetics, diarrhoea, fever, chills, cramping, altered taste etc.)

- Need for blood transfusion 
- Need for suction evacuation/admission

- Their level of satisfaction with the method.

Patients reporting with incomplete abortion and hemorrhagic morbidity were offered immediate surgical evacuation.

Primary outcomes measured were completeness of abortion, drug abortion interval.

Secondary outcomes noted were severity of side effects, amount of bleeding, need for analgesia, level of satisfaction with the method. They were also asked to use Likert scale (highly satisfied, very satisfied, partially satisfied, satisfied, not at all satisfied) to rate the acceptability of medical abortion regarding the time taken for abortion, vaginal bleeding, abdominal pain, adverse effects, overall acceptability and whether they would recommend this regimen to a friend or choose similar regimen again if required. Selection of any of the first three options on Likert scale by the patient was considered as an acceptable response.

\section{Statistical analysis}

Categorical variables were presented in number and percentage (\%) and continuous variables were presented as mean $\pm \mathrm{SD}$ and median. Normality of data was tested by
Kolmogorov-Smirnov test. If the normality was rejected then non parametric test was used.

\section{Statistical tests were applied as follows}

- Quantitative variables were compared using unpaired t-test/Mann-Whitney test (when the data sets were not normally distributed) between the two groups

- Qualitative variables were compared using Chisquare test /Fisher's exact test.

A p-value of $<0.05$ was considered statistically significant. The data was entered in MS Excel spreadsheet and analysis was done using Statistical Package for Social Sciences (SPSS) version 21.0.

\section{RESULTS}

One hundred pregnant women with gestation less than 7 weeks attending outpatient department of obstetrics and gynaecology formed the subject matter for this study. Women were assigned to two groups, group A, who received $200 \mathrm{mg}$ Mifepristone orally with Misoprostol administration by buccal route and Group B received 200 mg Mifepristone orally with Misoprostol administration by vaginal route. Various demographic parameters were comparable in both the groups and are shown in Table 1.

Table 1: Comparison of demographic parameters.

\begin{tabular}{|lll|l|}
\hline Demographic parameter & & Buccal & Vaginal \\
\hline Age distribution & & $29.22 \pm 0.08$ & $30.38 \pm 3.56$ \\
\hline \multirow{2}{*}{ Socioeconomic status } & Lower middle & $24.00 \%$ & $24.00 \%$ \\
\cline { 2 - 4 } & Upper middle & $76.00 \%$ & $76.00 \%$ \\
\hline \multirow{2}{*}{ Rural/urban } & Rural & $10.00 \%$ & $14.00 \%$ \\
\hline \multirow{3}{*}{ Education } & Urban & $90.00 \%$ & $86.00 \%$ \\
\hline & Intermediate & $12 \%$ & $10 \%$ \\
\hline Hean period of gestation & Gigh school & $2 \%$ & $2 \%$ \\
\cline { 2 - 4 } & Graduate & $52 \%$ & $48 \%$ \\
\cline { 2 - 4 } & Post graduate & $34 \%$ & $40 \%$ \\
\hline
\end{tabular}

The mean age in the buccal group was 29.22 years and in the vaginal group it was 30.38 years which was comparable in both groups. In the study, the mean gestational age of women was $5.47 \pm 0.52$ in the buccal group and $5.43 \pm 0.57$ weeks in the vaginal group respectively. Both the groups were comparable based on their gestational age. $(\mathrm{P}$ value $=0.601)$.

The mean drug abortion interval was found to be $11.16 \pm 2.61$ hours in the buccal group while it was found to be $12.32 \pm 3.63$ hours in the vaginal group. The two groups were comparable with respect to drug abortion interval ( $\mathrm{p}$ value $=0.157)$. 48 out of 50 women in group A $(96 \%)$ whereas 50 out of 50 women in group B $(98 \%)$ had complete abortion. There were two cases in buccal group which failed to abort completely and were surgically evacuated. However there were no unsuccessful cases in the vaginal group.

$P$ value was 0.495 which means the difference in efficacy in terms of complete abortion amongst the two groups is not statistically significant, meaning thereby that both the routes were equally effective. Upon comparing the level of satisfaction with the method of abortion in both the 
groups, it was found that women in both the groups buccal as well as vaginal were equally satisfied with the method employed. As shown in Table 2, in the study nausea and vomiting was present in 10 out of 50 women (20.00\% women) in group A and 31 out of 50 women
$(62.00 \%$ women) in group B. P value was $<0.005$ which is statistically significant. The side effects in terms of nausea and vomiting were significantly less with buccal route of Misoprostol as compared to vaginal route of Misoprostol.

Table 2: Comparison of side effects in buccal versus vaginal groups in this study.

\begin{tabular}{|lllll|}
\hline \multirow{2}{*}{ Side effects } & & Buccal & Vaginal & Mean \\
\hline \multirow{2}{*}{ Nausea, vomiting } & No & $80.00 \%$ & $38.00 \%$ & $59 \%$ \\
\cline { 2 - 5 } Fever and chills & Yes & $20.00 \%$ & $62.00 \%$ & $41 \%$ \\
\hline \multirow{2}{*}{ Diarrhoea } & No & $64.00 \%$ & $34.00 \%$ & $49.00 \%$ \\
\cline { 2 - 5 } & No & $36.00 \%$ & $66.00 \%$ & $51.00 \%$ \\
\hline \multirow{2}{*}{ Abdominal cramps } & Yes & $92.00 \%$ & $66.00 \%$ & $79.00 \%$ \\
\hline \multirow{2}{*}{ Altered taste } & No & $8.00 \%$ & $34.00 \%$ & $21.00 \%$ \\
\cline { 2 - 5 } & Yes & $14.00 \%$ & $22.00 \%$ & $18.00 \%$ \\
\hline & No & $86.00 \%$ & $78.00 \%$ & $82.00 \%$ \\
\hline
\end{tabular}

Table 3: Comparison of side effects in various other studies.

\begin{tabular}{|c|c|c|c|c|c|c|c|}
\hline Study & $\begin{array}{l}\text { No. of } \\
\text { patients }\end{array}$ & $\begin{array}{l}\text { Period of } \\
\text { gestation }\end{array}$ & Route & $\begin{array}{l}\text { Nausea and } \\
\text { vomiting }\end{array}$ & $\begin{array}{l}\text { Fever and } \\
\text { chills }\end{array}$ & Cramps & Diarrhoea \\
\hline \multirow{2}{*}{ Garg G et al } & \multirow{2}{*}{50} & \multirow{2}{*}{6.131} & Buccal & $24 \%$ & $4 \%$ & 4.84 & Nil \\
\hline & & & Vaginal & $32 \%$ & $4 \%$ & 5.12 & Nil \\
\hline Alam A et al & 651 & $<9$ & Buccal & $20.7 \%$ & $20 \%$ & Nil & Nil \\
\hline Lohr PA et al & 1250 & $<9$ & Buccal & $62 \%$ & Nil & Nil & Nil \\
\hline \multirow{2}{*}{ Crowden et al } & \multirow{2}{*}{168} & \multirow{2}{*}{$<9$} & Oral & - & $1 \%$ & Nil & Nil \\
\hline & & & Buccal & - & $10 \%$ & Nil & Nil \\
\hline \multirow{2}{*}{ Middleton $\mathrm{T}$ et al } & \multirow{2}{*}{442} & \multirow{2}{*}{$<8$} & Buccal & $70 \%$ & - & Equivalent & Insignificant \\
\hline & & & Vaginal & $62 \%$ & - & Equivalent & Insignificant \\
\hline \multirow{2}{*}{ Present study } & \multirow{2}{*}{100} & \multirow{2}{*}{$<7$} & Buccal & $20 \%$ & $36 \%$ & $86 \%$ & $8 \%$ \\
\hline & & & Vaginal & $62 \%$ & $66 \%$ & $78 \%$ & $34 \%$ \\
\hline
\end{tabular}

Table 4: Comparision of level of satisfaction with the method amongst women in group A (buccal Misoprostol) and group B (vaginal Misoprostol).

\begin{tabular}{|llll|}
\hline Level of satisfaction & Route & Vaginal & Total \\
\hline Not at all satisfied & Buccal & $0(0.00 \%)$ & $2(2.00 \%)$ \\
\hline Partially satisfied & $2(4.00 \%)$ & $5(10.00 \%)$ & $9(9.00 \%)$ \\
\hline Satisfied & $4(8.00 \%)$ & $19(38.00 \%)$ & $30(30.00 \%)$ \\
\hline Very satisfied & $11(22.00 \%)$ & $6(12.00 \%)$ & $19(19.00 \%)$ \\
\hline Highly satisfied & $13(26.00 \%)$ & $20(40.00 \%)$ & $40(40.00 \%)$ \\
\hline Total & $20(40.00 \%)$ & $\mathbf{5 0}(\mathbf{1 0 0 . 0 0 \%})$ & $\mathbf{1 0 0}(\mathbf{1 0 0 . 0 0 \% )}$ \\
\hline
\end{tabular}

Shivering and fever was present in 18 out 50 women (36.00\% women) belonging to group A and 33 out of 50 women $(66.00 \%$ women) belonging to group $\mathrm{B}$. P value was found to be less than 0.005 which is statistically significant meaning shivering and fever was less in women who took buccal Misoprostol as compared to women taking vaginal Misoprostol. Just 4 out of the 50 women $(8.00 \%)$ taking buccal Misoprostol had diarrhoea (groupA) whereas 17 out of 50 women (34.00\% women) taking vaginal Misoprostol, belonging to group B suffered from diarrhoea. $\mathrm{P}$ value was 0.003 meaning thereby that the difference in the occurrence of diarrhoea was statistically different in the two groups and women in vaginal group had more diarrheas. 
It was found that 23 out of the 50 women (46.00\%) taking buccal Misoprostol had altered taste (group A) whereas no women taking vaginal misoprostol, belonging to group $\mathrm{B}$ suffered from altered taste. $\mathrm{P}$ value was $<0.005$ meaning thereby that the difference in the occurrence of altered taste was statistically significant in the two groups and women in buccal group had more altered taste. Abdominal cramps was present in 43 out 50 women $(86.00 \%$ women) belonging to group A and 39 out of 50 women ( $78.00 \%$ women) belonging to group B. There is no difference in the incidence of abdominal cramps in women taking Misoprostol by either buccal or vaginal route. In the study all the patients reported atleast one side effect with Misoprostol and most of the patients have more than one side effect.

Analgesia was needed in 34 women out of 50 (68.00\% of women) in group A (buccal) and 29 out of 50 women (58.00\% of women) in group B (vaginal).

There was no statistical significance between the two groups in terms of need for analgesia.

\section{DISCUSSION}

More than 200 million women in the developing countries want to prevent pregnancy but are not using any modern contraception leaving poor women facing a substantial risk of unintended pregnancy, unsafe abortion, maternal and infant mortality and morbidity. ${ }^{4}$ With the ever increasing world population, termination of pregnancy or induced abortion is a subject no country in the world can do without. In fact in the present knowledge induced abortion is the third most common means of fertility control next to sterilization and oral contraception. In the study, patients were randomized of first trimester into two groups to receive Misoprostol by either buccal or vaginal route, 48 hours after oral Mifepristone, based on block randomization, who fulfilled the inclusion criteria. Both the groups were comparable in terms of age, period of gestation, socioeconomic status and various other demographic factors.

In the study 48 out of 50 women in group A $(96 \%)$ whereas 50 out of 50 women in group B $(100 \%)$ had complete abortion thus making efficacy $96 \%$ in buccal group and $100 \%$ in vaginal group. The results were comparable to a study by Middleton $\mathrm{T}$ et al, and compared the efficacy of medical abortion via buccal versus vaginal route for pregnancies upto 56 days from LMP. ${ }^{5}$ The efficacy rate was found to be $95 \%(205 / 216)$ in the buccal group and 93\% (199/213) in the vaginal group $\left(\mathrm{chi}^{(2)}=0.43\right)$. Also the efficacy as judged by complete abortion was 96 and $88 \%$ in buccal and vaginal group, respectively in the study by Garg $\mathrm{G}$ et al when they compared the results of buccal versus vaginal Misoprostol administration in first trimester abortions. ${ }^{6}$ In their study about efficacy and acceptability of a Mifepristone - Misoprostol combined regimen for early induced abortion among women in Mexico City, Melanie Peña et al found that the overall efficacy of the combined medical abortion regimen using buccal route for misoprostol studied was $97.3 \%(n=945){ }^{7}$

In the study the mean drug abortion interval was found to be comparable in both buccal as well as in the vaginal group (11.16 \pm 2.61 in buccal group versus $12.32 \pm 3.63$ in vaginal group). However in the study by Li YT et al, the mean drug abortion interval was found to be 5.8 hours which is not similar to the results. ${ }^{8}$

The side effects in terms of nausea and vomiting were significantly less with buccal route of Misoprostol as compared to vaginal route of Misoprostol. This was found to be similar to the study by Geetika $\mathrm{G}$ et al, and also similar to the findings in the study by Alam A et al, Shivering and fever was less in women who took buccal Misoprostol as compared to women taking vaginal Misoprostol. ${ }^{9}$ The difference in the occurrence of altered taste was statistically significant in the two groups and women in buccal group had more altered taste. Analgesia was needed in 34 women out of 50 (68.00\% of women) in group A (buccal) and 29 out of 50 women $(58.00 \%$ of women) in group B (vaginal). This was comparable to the study by Alam A et al, this has been explained in Table 3. ${ }^{9}$

In the study women in both the groups buccal as well as vaginal were equally satisfied with the method employed as evident in Table 4. In the study by Philip Goldstone et al, where overall there was a high level of satisfaction with the Mifepristone - buccal Misoprostol regimen used, with most women. ${ }^{10}$ Also the results were comparable to studies by by Garg $\mathrm{G}$ et al and by Alam A et al. ${ }^{6,9}$ Thus, the buccal regimen has an acceptable success rate and may provide a new treatment alternative for women uncomfortable with inserting Misoprostol vaginally in the first trimester.

\section{CONCLUSION}

Buccal Misoprostol is comfortable and easier to administer when compared to other routes and it has potential to be developed as a self- administered regimen. Buccal Misoprostol is as efficacious as vaginal Misoprostol with significantly lesser side effects upto 7 weeks of period of gestation.

Funding: No funding sources

Conflict of interest: None declared

Ethical approval: The study was approved by the Institutional Ethics Committee

\section{REFERENCES}

1. Singh S, Wulf D, Hussain R, Bankole A, Sedgh G. Abortion worldwide: A decade of uneven Progress. New York: Guttmacher Institute; 2009. 
2. India. Go . The Medical Termination of Pregnancy Act, (Act No 34, 1971) and MTP rules and regulations, Vide G.S.R. 2543, 1975. New Delhi: Gazette of India; 1975.

3. Lohr PA, Reeves MF, Hayes JL. Oral mifepristone and buccal misoprostol administered simultaneously for abortion: a pilot study. Contracept. 2007;76:21520.

4. Population Council, International Federation of Gynecology and Obstetrics (FIGO), and Reproductive Health Supplies Coalition. "2013 Statement from the Bellagio Group on LARCs: Long-Acting Reversible Contraception in the Context of Full Access, Full Choice. 2013. Available At www.popcouncil.org/pdfs/2013RH_Bellagio Consensus.pdf.

5. Middleton T, Schaff E, Fielding SL, Scahill M, Shannon C, Westheimer E, et al. Randomized trial of mifepristone and buccal or vaginal misoprostol for abortion through 56 days of last menstrual period. Contraception. 2005;72(5):328-32.

6. Geetika G, Navneet T, Alka S. Buccal versus vaginal misoprostol administration for the induction of first and second trimester abortions. J Obst Gynecol. 2015;2:111-6.

7. Peña M, Dzuba IG, Smith PS, Mendoza LJ, Bousiéguez M, Martínez ML. Efficacy and acceptability of a mifepristone - misoprostol combined regimen for early induced abortion among women in Mexico City. Int $\mathbf{J}$ Gynec Obst. 2014;04:12.

8. Li YT, Hsieh JC, Hou GQ, Chen TH, Chu YC, Lin TC, et al. Simultaneous use of mifepristone and misoprostol for early pregnancy termination. Taiwan J Obstet Gynecol. 2011;50(1):11-4.

9. Alam A, Bracken H, Johnston HB, Raghavan S, Islam N, Winikoff B. Acceptability and feasibility of mifepristone-misoprostol for menstrual regulation in Bangladesh. Int Perspect Sex Reprod Health. 2013;39(2):79-87.

10. Goldstone P, Michelson J, Williamson E. Early medical abortion using low - dose mifepristone followed by buccal misoprostol. Medical J Austrailia. 2012;197(5):282-6.

Cite this article as: Khan N, Kant AM, Thukra PC, Saquib M. Comparison of efficacy of buccal versus vaginal misoprostol in first trimester induced abortion. Int J Reprod Contracept Obstet Gynecol. 2019;8:3368-3. 